\title{
HPTLC Densitometric Quantification of Kaempferol from Leaves of Euphorbia neriifolia
}

\author{
Prashant Y. Mali*, Swapnil Goyal \\ Department of Pharmacology, BR Nahata College of Pharmacy, Mandsaur University, Mandsaur, Madhya Pradesh, INDIA.
}

\begin{abstract}
Objectives: To study HPTLC densitometric quantification of kaempferol in aqueous extract fraction (EN6) of leaves of Euphorbia neriifolia Linn. Methods: Chromatographic method was employed on pre-washed and pre-activated $10.0 \times 10.0 \mathrm{~cm}$ aluminum Lichrosphere HPTLC plates pre-coated by silica gel $60 \mathrm{~F}_{254}$ of $0.2 \mathrm{~mm}$ thickness layer as a stationary phase. Solvent system toluene: ethyl acetate: formic acid $(6: 4: 1 \mathrm{v} / \mathrm{v} / \mathrm{v})$ was used. Densitometric analysis of kaempferol was carried out at $254 \mathrm{~nm}$ in absorptionreflectance mode. Percent content of kaempferol was quantified using proposed HPTLC densitometric method. The method was validated by ICH guidelines for its linear range, linearity, LOD and LOQ, specificity, precision, reproducibility and recovery studies. Results: HPTLC finger printing analysis showed that $R_{f}$ value of peak of kaempferol (Rf 0.91 ) was closely compacted with aqueous extract fraction (EN6; $R_{f} 0.90$ ) that indicates identification of kaempferol. Percent content of kaempferol was quantified and found to be $0.024817 \%$ in aqueous extract fraction (EN6) for $10 \mu \mathrm{l}$ volume applied. Linear range was found $100-600 \mathrm{ng} / \mathrm{spot}$ with correlation coefficient 0.99834 . LOD and LOQ were found 100 and $300 \mathrm{ng}$. Proposed method was specific. The \% CV for intra-day was 2.422 and inter-day was 2.522 at concentration of $400 \mathrm{ng} / \mathrm{spot}$. The \% CV was found 2.1, hence the method was reproducible. Average percent recovery was $95.57 \%$ in aqueous extract fraction (EN6), therefore, the method was found to be accurate. Conclusion: Developed HPTLC method was found to be simple, specific, precise, reproducible and accurate. Here, the first time we have reported HPTLC method for kaempferol in aqueous extract fraction (EN6). However, there is a requirement to carry forward these studies by using some other standard markers in aqueous extract fraction (EN6) of E. neriifolia leaves for exploring its phyto-constituents that could have therapeutic potential in various diseases.
\end{abstract}

Key words: Euphorbia neriifolia Linn., Aqueous extract fraction, Leaves, HPTLC, Kaempferol, Identification, Quantification, Validation.

\section{INTRODUCTION}

High performance thin layer chromatography (HPTLC) has become a regular investigative method due to its cost effectiveness and reliability in quantification of analyte at micro and nano gram levels. It is proved that HPTLC was very useful method for the reason of high sample throughput and requires minimum sample clean-up with less analysis or detection time. ${ }^{1}$ The multi-coloured HPTLC images have provides an additional instinctive parameter of visible colour and fluorescence and unlike G.C and HPLC. Simultaneously HPTLC method can determine various samples on the same plate. This approach helps to sustain its instinctive advantage along with to find limitations of developing distance and plate efficiency. ${ }^{2}$

Euphorbia neriifolia Linn. Sp. Pl. (451.1753) belonging to family Euphorbiaceae. It is worldwide scattered in Baluchistan, Burma, India and Malaysian Islands. In India, it is found in rocky ground throughout Deccan Peninsula and Orissa. It is habitually cultivated for hedges in villages all over India., ${ }^{3,4}$. nerrifolia leaves has several ethnomedicinal uses. As leaves are brittle, heating, carminative, improve the appetite,
Submission Date: 21-04-2020; Revision Date: 30-06-2020; Accepted Date: 13-08-2020

DOI: 10.5530/ijper.54.3s.158 Correspondence: Mr. Prashant Y Mall Research Scholar, Department of Pharmacology, BR Nahata College of Pharmacy, Mandsaur University, Mandsaur, Madhya Pradesh, INDIA.

Phone: +919822284089 E-mail: pymali2008@ rediffmail.com

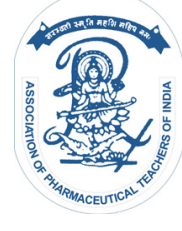

www.ijper.org 
good for treatment of tumors, pain, inflammation, abdominal swelling and bronchial infection. ${ }^{5}$ Various plant parts or whole E. neriifolia extract and its isolates have been reported scientifically using various in-vivo and in-vitro experimental methods for anti-carcinogenic / renal carcinogenesis/ hepatocarcinogenesis, ${ }^{6-9}$ antidiabetic, ${ }^{10}$ cytotoxicity, ${ }^{11,12}$ immunomodulatory, ${ }^{13,14}$ etc. properties. E. neriifolia is also reported to have neriifolin-S, ${ }^{15}$ neriifolin, ${ }^{16}$ neriifoliene, ${ }^{17}$ euphol, ${ }^{18}$ neriifolione and cycloartenol, ${ }^{19}$ taraxerol, ${ }^{20}$ quercetin and rutin, ${ }^{21}$ antiquorin, ${ }^{22}$ etc. phyto-constituents.

As per earlier report of percentage yields and primary phytochemical screening of extract fractions (EN1 to EN6) of E. neriifolia leaves. ${ }^{23}$ The percentage yield of petroleum ether (EN1; $7.8 \%$ yield), toluene (EN2; $1.19 \%$ yield), chloroform (EN3; $0.56 \%$ yield), ethyl acetate (EN4; 2.36\% yield), n-butanol (EN5; 0.26\% yield) and aqueous (EN6; 8.5\% yield) was found. Among the findings of primary phytochemical screening of extract fractions (EN1 to EN6), the aqueous extract fraction (EN6) was comprised the presence of amino acids, alkaloids, flavonoids, carbohydrates, proteins, glycosides, saponin, tannins, steroids and phenols class of phytocompounds. In reference with these studies, the aqueous extract fraction (EN6) was selected for primary HPTLC fingerprinting analysis. The HPTLC reports have also showed there is a presence of flavonoids, terpenes, steroidal saponins, alkaloids, glycosides, tannins and phenolic acids, etc. class of phyto-constituents. In present investigation authors have been reported identification, quantification and validation of kaempferol in EN6 extract fraction of leaves of E. neriifolia by HPTLC technique.

\section{MATERIALS AND METHODS}

\section{Chemicals}

All the chemicals used were of analytical grade and purchased from Merck, Germany and Sd Fine-Chem, Mumbai, India. Kaempferol (purity: 98.8\% w/w) was purchased from Natural Remedies Pvt. Ltd., Bangalore, India.

\section{Collection and authentication of $E$. neriifolia and its leaves}

E. neriifolia plant and its leaves were collected from local region of Bhopal, Madhya Pradesh, India. Dr. Vijay V. Bhadane, Taxonomist, Department of Botany, Pratap College, Amalner-425401, Maharashtra, India was authenticated. Voucher specimen (No. PCA/BotP1637) was assigned and deposited in the department.

\section{Extraction and fractionation of $E$. neriifolia leaves}

The detailed procedure of extraction and fractionation of E. neriifolia leaves was mentioned in our earlier report. ${ }^{23}$ Obtained extract fractions were concentrated, dried and designated as petroleum ether (EN1), toluene (EN2), chloroform (EN3), ethyl acetate (EN4), n-butanol (EN5) and aqueous (EN6) and used for HPTLC densitometric quantification of kaempferol.

\section{Preparation of solution of aqueous extract fraction (EN6) of E. neriifolia leaves}

Accurately weighted $500 \mathrm{mg}$ aqueous extract fraction (EN6) was dissolved into $5 \mathrm{ml}$ of methanol in volumetric flask separately. It was then sonicated for $20 \mathrm{~min}$. The solution was kept a side for $30 \mathrm{~min}$ to settle down the aliquot. The concentration $100 \mu \mathrm{g} / \mu \mathrm{l}$ of aqueous extract fraction was used in the study.

\section{Preparation of standard solution of kaempferol}

Accurately weighted $5 \mathrm{mg}$ of kaempferol was dissolved into $5 \mathrm{ml}$ of methanol in volumetric flask. It was then sonicated for $15 \mathrm{~min}$., $1 \mathrm{ml}$ of this dilution was transferred into $10 \mathrm{ml}$ volumetric flask and volume was adjusted with methanol to get the final concentration $0.1 \mu \mathrm{g} / \mu \mathrm{l}$ of kaempferol.

\section{Solvent system}

After several trails on different solvent systems, the better resolution was found in toluene: ethyl acetate: formic acid $(6: 4: 1 \mathrm{v} / \mathrm{v} / \mathrm{v})$ and used for co-chromatography with kaempferol.

\section{Chromatographic conditions and HPTLC fingerprinting for kaempferol}

We have developed chromatographic conditions in this study, performed on pre-washed and pre-activated $10.0 \times 10.0 \mathrm{~cm}$ aluminum Lichrosphere HPTLC plates pre-coated by silica gel $60 \mathrm{~F}_{254}$ of $0.2 \mathrm{~mm}$ thickness layer (Merck, Germany). Volumes of aqueous extract fraction (EN6) were applied at 5 and $10 \mu \mathrm{l}$ and 2 and 5 $\mu \mathrm{l}$ of kaempferol at application position $8.00 \mathrm{~mm}$ with band length $8.00 \mathrm{~mm}$ by a Camag Linomat- $V$ automatic HPTLC sample spotter (Camag) equipped with a 25 $\mu \mathrm{l}$ syringe (Hamilton) in continuous drying stream of nitrogen gas. Linear ascending development with solvent system, toluene: ethyl acetate: formic acid (6:4:1 $\mathrm{v} / \mathrm{v} / \mathrm{v})$ ina $10.0 \mathrm{x} 10.0 \mathrm{~cm}$ twin trough glass chamber (Camag) formally saturated with solvent system for $15 \mathrm{~min}$ at relative humidity $(40 \%)$ and room temp. $\left(25 \pm 2^{\circ} \mathrm{C}\right)$. The development distance was $70.00 \mathrm{~mm}$ (development time $20 \mathrm{~min}$ with filter paper) and $20 \mathrm{ml}$ solvent system was used. After development, plate was dried with stream of hot air and densitometric scanning 
was performed at $254 \mathrm{~nm}$ in absorption-reflectance mode by using a Camag HPTLC scanner 3 and Camag visualizer with automatic digital camera linked to winCATS software (Version 1.4.6). The slit dimension of scanner at $6.00 \times 0.45 \mathrm{~mm}$ (Micro) was set with 100 $\mu \mathrm{m} / \mathrm{step}$ data resolution and $20 \mathrm{~mm} / \mathrm{s}$ scanning speed. The fingerprinting of kaempferol was confirmed by superimposing the U.V spectra of aqueous extract fraction (EN6) and standard kaempferol within $\mathrm{R}_{f} \pm 0.1$ values, scanned at $254 \mathrm{~nm}$ under D2 lamp with 190-400 $\mathrm{nm}$ start and end wavelengths. Colors of resolved bands were noted.

\section{Preparation of calibration curve of kaempferol}

Stock solution of kaempferol $(0.1 \mu \mathrm{g} / \mu \mathrm{l})$ was prepared in methanol. Different volumes of stock solution 1, 2, 3, 4, 5 and $6 \mu \mathrm{l}$ of kaempferol were applied on HPTLC plate to obtained concentration 100, 200, 300, 400, 500 and $600 \mathrm{ng} / \mathrm{spot}$ (Band width: $8 \mathrm{~mm}$, distance between tracks $13.3 \mathrm{~mm}$ ) using automatic sampler spotter. The developed plate was scanned at $254 \mathrm{~nm}$ under D2 lamp with 190-400 $\mathrm{nm}$ start and end wavelengths. Linear regression of standard curve was determined through $R^{2}$ $\pm \mathrm{SD}=0.99834 \pm 3.53 \%$ and linear regression equation was $\mathrm{y}=-86.03+10.56 * \mathrm{X}$. The regression statistics was showed good linear relationship over the concentration range of 100-600 ng/spot. The calibration curve of kaempferol was obtained by plotting peak areas (AU) verses concentration (ng/spot) of kaempferol applied with the help of winCATS software (Version 1.4.6) as shown is (Figure 1).

\section{Quantification of kaempferol in aqueous extract fraction (EN6)}

Quantification of kaempferol in aqueous extract fraction (EN6) was performed by applying $10 \mu \mathrm{l}$ of suitably diluted each extract fraction in triplicates on HPTLC plate. Developed plate was scanned at $254 \mathrm{~nm}$ under D2 lamp with 190-400 nm start and end wavelengths. The peak areas were recorded and amount of kaempferol was calculated. Therefore, based on the amount of kaempferol found, the percent content of kaempferol in aqueous extract fraction (EN6) was calculated.

\section{Validation of developed HPTLC method for kaempferol}

$\mathrm{ICH}$ guidelines were followed for the validation of developed HPTLC method for kaempferol (Topic Q2B - Step 4, Nov. 1996, CPMP/ICH/281/95 and Topic Q2 (R1) - Step 5, June 1995, CPMP/ICH/381/95) for its linear range, linearity (correlation coefficient), limit of detection (LOD) and limit of quantification
(LOQ) (sensitivity), specificity (selectivity), precision (variation or variability), reproducibility and recovery (accuracy). ${ }^{24-26}$

\section{Linear range}

Linear range was determined by applying 1, 2, 3, 4, 5 and $6 \mu \mathrm{l}$ of kaempferol on HPTLC plate to obtained concentration 100, 200, 300, 400, 500 and $600 \mathrm{ng} /$ spot using automatic sampler spotter. Developed plate was scanned as mentioned in above chromatographic conditions and HPTLC fingerprinting for kaempferol section.

\section{Linearity}

Linearity of kaempferol was determined by plotting linearity curve of peak area (AU) verses concentration (ng/spot) of kaempferol as described in chromatographic conditions and HPTLC fingerprinting for kaempferol section. The correlation coefficient ( $\mathrm{r}$ or $\left.r^{2}\right)$ and standard deviation (SD) of the calibration curves were estimated to determine the linearity of method.

\section{LOD and LOQ}

Sensitivity of method was determined by evaluating LOD and LOQ. Various concentrations of standard solutions of kaempferol were applied along with methanol as blank. LOD was determined on the basis of signal to noise ratio $(\mathrm{S} / \mathrm{N})$ of $3: 1$ and $L O Q$ was $(\mathrm{S} / \mathrm{N})$ of 10:1.

\section{Specificity}

Specificity of developed method was studied by assay and impurity technique. The aqueous extract fraction (EN6), standard kaempferol, mobile phase used for kaempferol and methanol used as a diluent were applied simultaneously on the HPTLC plate and linear ascending development with the solvent system, toluene: ethyl acetate: formic acid $(6: 4: 1 \mathrm{v} / \mathrm{v} / \mathrm{v})$ in a $10.0 \mathrm{x} 10.0 \mathrm{~cm}$ twin trough glass chamber (Camag) formerly saturated with solvent system for $15 \mathrm{~min}$ at relative humidity $(40 \%)$ and room temp. $\left(25 \pm 2^{\circ} \mathrm{C}\right)$. The development distance was $70.00 \mathrm{~mm}$ (development time $20 \mathrm{~min}$ with filter paper) and $20 \mathrm{ml}$ solvent system was used. After development, plate was dried with a stream of hot air and densitometric scanning was performed at $254 \mathrm{~nm}$ in absorption-reflectance mode by using a Camag HPTLC scanner 3 and Camag visualizer with automatic digital camera linked to win-CATS software (Version 1.4.6). The spot of kaempferol in aqueous extract fraction (EN6) was confirmed by comparing $\mathrm{R}_{f}$ value and superimposed spectra. 


\section{Precision}

Variability of method was studied by evaluating nine aliquots of standard solution containing $400 \mathrm{ng} / \mathrm{spot}$ of kaempferol on same day (Intra-day) and on different days (Inter-day). Precision was expressed as coefficient of variation $(\mathrm{CV} \%)$ of calculated concentrations of each calibration level.

\section{Reproducibility}

Reproducibility of method was performed by evaluating nine aliquots of standard solution containing $400 \mathrm{ng} /$ spot of kaempferol. Reproducibility was expressed as coefficient of variation (CV \%) of measured concentrations of each calibration level.

\section{Recovery}

Recovery studies were performed by spiking known amounts of marker corresponding to $80 \%, 100 \%$ and $120 \%$ of kaempferol on the aqueous extract fraction (EN6). Each level was analyzed in triplicates. The recovery of kaempferol at different levels in aqueous extract fraction (EN6) fraction was calculated.

\section{RESULTS}

\section{HPTLC fingerprinting and co-chromatography}

The chromatograph of aqueous extract fraction (EN6) and kaempferol with their $\mathrm{R}_{f}$ values and colour of band resolved where taken into consideration for identification as shown in (Table 1 and Figure 2 and Figure 3). $\mathbf{R}_{f}$ value of peak of kaempferol $\left(\mathrm{R}_{f} 0.91\right)$ was closely compacted with $\mathrm{R}_{f}$ value of peak of aqueous extract fraction (EN6; $\left.\mathrm{R}_{f} 0.90\right)$.

\section{Quantification of kaempferol in aqueous extract fraction (EN6)}

There was no report of quantification of kaempferol in aqueous extract fraction (ENG) of E. neriifolia leaves by

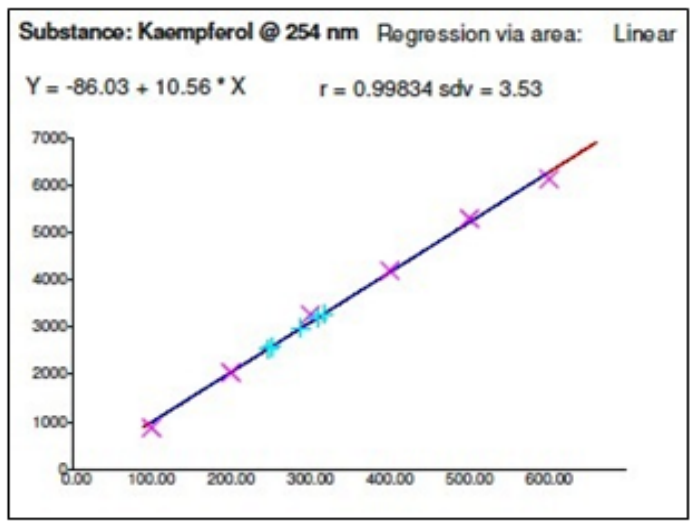

Figure 1: Calibration curve for standard kaempferol $(n=6)$. using HPTLC technique. Therefore, we have developed a simple and precise method for quantification of kaempferol. HPTLC procedure was optimized by a view to quantify herbal extracts. The solvent system toluene: ethyl acetate: formic acid $(6: 4: 1 \mathrm{v} / \mathrm{v} / \mathrm{v})$ gave better, sharp and well-defined peak resolution. Developed HPTLC plate of kaempferol and aqueous extract fraction (EN6) for quantification was scan at 254 $\mathrm{nm}$ before and $366 \mathrm{~nm}$ after derivatization. The percent content of kaempferol was quantified using proposed HPTLC densitometric method. It was found to be $0.024817 \%$ in aqueous extract fraction (EN6) for the 10 $\mu \mathrm{l}$ volume applied.

\section{Validation of developed HPTLC method for kaempferol}

\section{Linear range}

Linear range for kaempferol was 100-600 ng/spot with correlation coefficient 0.99834 (Table 2).

\section{LOD and LOQ}

LOD for kaempferol was100 ng and LOQ was $300 \mathrm{ng}$ which indicated adequate sensitivity of the method. LOD and LOQ were determined from slope of the lowest part of calibration plot. This also indicated that proposed method exhibits a good sensitivity for quantification of kaempferol (Table 2).

\section{Specificity}

Proposed method was found to be specific for kaempferol quantification (Table 2).

\section{Precision}

The peak area was measured at nine different concentration levels which showed \% CV for intraday was 2.422 and inter-day was 2.522 at concentration of $400 \mathrm{ng} / \mathrm{spot}$ (Table 3). As per ICH guidelines, the acceptance criteria for precision were $\% \mathrm{CV} \leq 2 \%$ when
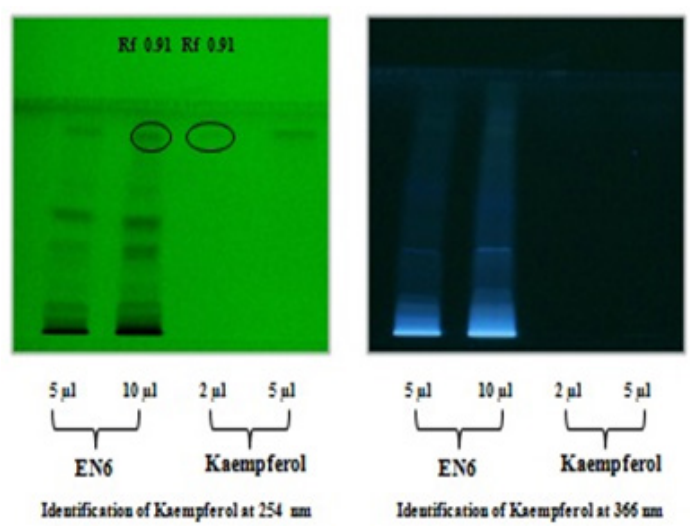

Figure 2: Scanned HPTLC plate using EN6 extract fraction and standard kaempferol at $254 \mathrm{~nm}$ and $366 \mathrm{~nm}$ 
Table 1: $\mathbf{R}_{f}$ value and colour of band for identification of kaempferol in aqueous extract fraction (EN6) at $254 \mathrm{~nm}$.

\begin{tabular}{|c|c|c|}
\hline Samples & $\boldsymbol{R}_{\boldsymbol{f}}$ value & Colour of band \\
\hline Aqueous extract fraction (EN6) & 0.90 & Pink \\
\hline Kaempferol & 0.91 & Dark blue \\
\hline
\end{tabular}

Table 2: Method validation parameters for quantification of kaempferol by proposed HPTLC densitometric method.

\begin{tabular}{|c|c|}
\hline Parameters & Kaempferol \\
\hline Scanned wavelength & $254 \mathrm{~nm}$ \\
\hline Linear range (ng/spot) & $100-600$ \\
\hline LOD $(\mathrm{ng})$ & 100 \\
\hline LOQ $(\mathrm{ng})$ & 300 \\
\hline Linearity $\left(\mathrm{r}\right.$ or $\left.\mathrm{r}^{2}\right)$ & 0.99834 \\
\hline Specificity & Specific \\
\hline Reproducibility $(\% \mathrm{CV}, \mathrm{n}=6)$ & 2.1 \\
\hline
\end{tabular}

minimum of 6 determinations. But we have used nine different concentrations. Therefore, proposed method was found to be precise.

\section{Reproducibility}

The \% CV was found to be 2.1(Table 2). Hence, proposed method was reproducible.

\section{Recovery studies}

The average percent recovery was $95.57 \%$ for aqueous extract fraction (EN6), which was within the acceptable limits (Table 4). Hence, proposed method was found to be accurate.

\section{DISCUSSION AND CONCLUSION}

HPTLC has potential to identify more compounds than HPLC, even though its poor resolution. In this view, the compounds that cannot be eluted still can be detected. Furthermore, the compounds having no U.V absorption e.g. sugar still can be detected by reagent spraying. HPTLC chromatogram pattern assessment seems to be promising for identification of active compounds in plant extracts. Hence, HPTLC can be used as a tool in quality control in order to assurance that the active compounds are extracted. Through data analysis system and optimized experimental conditions, HPTLC is also possible for the expansion of chromatographic fingerprint techniques to identify and determine composite of plant extracts as like G.C and HPLC. ${ }^{27}$ In reference with the above statement,

\begin{tabular}{|c|c|c|c|}
\hline \multicolumn{4}{|c|}{ Table 3: Intra-day and inter-day precision of } \\
kaempferol. \\
\hline Marker & $\begin{array}{c}\text { Concentration } \\
\text { (ng/spot) }\end{array}$ & $\begin{array}{c}\text { Intra-day } \\
\text { precision* }\end{array}$ & $\begin{array}{c}\text { Inter-day } \\
\text { precision* }\end{array}$ \\
\hline Kaempferol & 400 & 2.422 & 2.522 \\
\hline
\end{tabular}

*Coefficient of variation $(\% \mathrm{CV}, n=9)$

\section{Table 4: Recovery studies of kaempferol at $80 \%$, \\ $100 \%$ and $120 \%$ addition by proposed HPTLC densitometric method.}

\begin{tabular}{|c|c|c|c|c|}
\hline Marker & $\begin{array}{c}\text { Amount } \\
\text { of marker } \\
\text { spiked (\%) }\end{array}$ & \begin{tabular}{c} 
Amount \\
of \\
marker \\
added \\
\cline { 3 - 4 }
\end{tabular} & $\begin{array}{c}\text { Recovery* } \\
(\boldsymbol{\mu})\end{array}$ & $\begin{array}{c}\text { Average } \\
\text { recovery } \\
(\%)\end{array}$ \\
\cline { 3 - 4 } & $\begin{array}{c}\text { Aqueous } \\
\text { extract } \\
\text { fraction } \\
\text { Kaempferol }\end{array}$ & $\begin{array}{c}\text { Aqueous } \\
\text { extract } \\
\text { fraction } \\
\text { (EN6) }\end{array}$ \\
\cline { 2 - 4 } & 100 & 2 & 96.21 & \multirow{2}{*}{95.57} \\
\cline { 2 - 4 } & 120 & 2.4 & 96.44 & \\
\hline
\end{tabular}

*average of three determinations

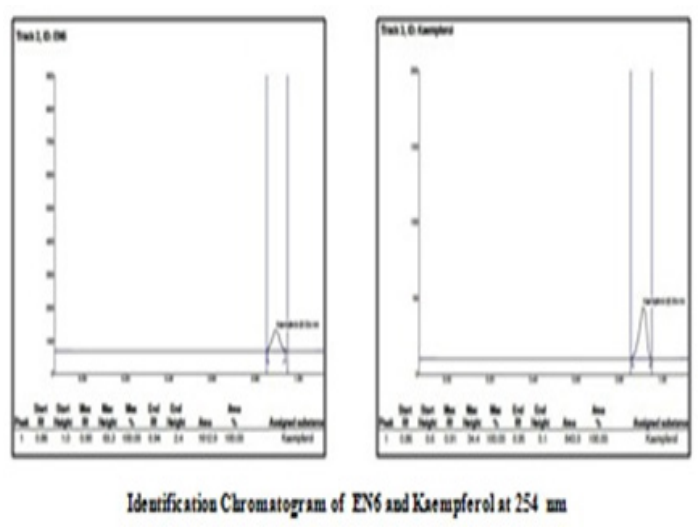

Figure 3: HPTLC chromatogram of EN6 extract fraction and standard kaempferol at $254 \mathrm{~nm}$.

we have studied chromatographic fingerprinting, quantification and validation of HPTLC method for standard marker kaempferol in aqueous extract fraction (EN6) of E. neriifolia leaves. The results of HPTLC finger printing analysis showed that $\mathrm{R}_{f}$ value of peak of kaempferol $\left(\mathrm{R}_{f}\right.$ 0.91) was closely compacted with aqueous extract fraction (EN6; $\left.\mathrm{R}_{f} 0.90\right)$ which indicates the identification of kaempferol. The percent content of kaempferol was quantified and found to be $0.024817 \%$ in aqueous extract fraction (EN6) for the $10 \mu \mathrm{l}$ volume applied. Linear range was found100-600 ng/spot with correlation coefficient 0.99834 . LOD and LOQ were found $100 \mathrm{ng}$ and $300 \mathrm{ng}$. The proposed method was specific. The $\% \mathrm{CV}$ for intra-day was 2.422 and interday was 2.522 at concentration of $400 \mathrm{ng} / \mathrm{spot}$. The $\%$ CV was found 2.1, hence the method was reproducible. 
The average percent recovery was $95.57 \%$ in aqueous extract fraction (EN6), therefore, the method was found to be accurate. Therefore, the developed HPTLC method was found to be simple, specific, precise, reproducible and accurate. Here, the first time we have reported this HPTLC method for kaempferol in the aqueous extract fraction (EN6). This HPTLC method has provided sufficient information and parameters for complete identification and separation of kaempferol. Hereby, it is also confirmed that the presence of kaempferol in the aqueous extract fraction (EN6) was justified its recognition in primary phytochemical studies, fluorescence and colour reactions examination. However, there is a requirement to carry forward these studies by using some other standard markers in the aqueous extract fraction (EN6) of E. neriifolia leaves for exploring its phyto-constituents that could have therapeutic potential in various diseases.

\section{ACKNOWLEDGEMENT}

Authors would like to thankful to Anchrom Test Lab Pvt. Ltd., Mumbai for availing the necessary facilities to perform this research work.

\section{CONFLICT OF INTEREST}

No conflicts of interest are declared.

\section{ABBREVIATIONS}

HPTLC: High performance thin layer chromatography; EN1: Petroleum ether extract fraction of E. neriifolia leaves; EN2: Toluene extract fraction of E. neriifolia leaves; EN3: Chloroform extract fraction of $E$. neriifolia leaves; EN4: Ethyl acetate extract fraction of E. neriifolia leaves; EN5: n-butanol extract fraction of E. neriifolia leaves; EN6: Aqueous extract fraction of E. neriifolia leaves; ICH: International Conference on Harmonization; LOD: Limit of detection; LOQ: Limit of quantification; \%: Percent / Percentage; CV: Coefficient of variation.

\section{REFERENCES}

1. Rathee D, et al. Simultaneous quantification of bergenin, $(+)$-catechin, gallicin and gallic acid and quantification of $\beta$-sitosterol using HPTLC from Bergeniaciliata(Haw.) Sternb. Forma ligulata Yeo (Pasanbheda). Pharm Anal Acta. 2010;1:104.

2. Kpoviessia DSS, et al. Validation of a method for the determination of sterols and triterpenes in the aerial part of Justicia anselliana (Nees) T. Anders by capillary gas chromatography. J Pharm Biomed Anal. 2008;48(4):1127-35.

3. Anonymous. The wealth of India. A dictionary of Indian raw materials and industrial products (raw materials), (D-E).New Delhi: Central Institute of Medicinal and Aromatic Plants. 2003;3.
4. Ved DK, Sureshchandra ST, Barve V, Srinivas V, Sangeetha S, Ravikumar $\mathrm{K}$, et al. Plant details. Bangalore: FRLHT's ENVISCentre on Medicinal Plants. 2016. Available from:http://envis.frlht.org/plant_details.php?disp_ id=936\& parname $=0$

5. Kirtikar KR, Basu BD. Indian medicinal plants. $2^{\text {nd }}$ ed., Allahabad: Lal it Mohan Basu. 2006;3.

6. Bigoniya P, Rana AC. Protective effect of Euphorbia neriifolia saponin fraction on CCl4-induced acute hepatotoxicity. Afri J Biotech. 2010;9(42):7148-56.

7. Sharma V, Janmeda P, Paliwal R, Singh L, Sharma V, Sharma S. Anticarcinogenic potential of $E$. neriifolia leaves against n-nitrosodiethylamineinduced nephrotoxicity in mice. Biochem Cell Arch. 2011;11(2):393-8.

8. Sharma V, Janmeda P. Chemopreventive role of Euphorbia neriifolia (Linn) and its isolated flavonoid against n-nitrosodiethylamine-induced renal histopathological damage in male mice. Toxicol Int. 2013;20(1):101-7.

9. Janmeda P, Sharma V, Singh L, Paliwal R, Sharma S, et al. Chemopreventive effect of hydroethanolic extract of Euphorbia neriifolia leaves against DENA induced renal carcinogenesis in mice. Asian Pac J Cancer Prev. 2011;12(3):677-83.

10. Mansuri MI, Patel VM. Anti-diabetic potential of Euphorbia nerifolia Linn. alloxan induced diabetic rats. Journal of Pharmacy Research. 2012;5(5):25713.

11. Babar RS, Kataware UP, Mali NN, Patil SB, Naikwade NS. In-vitro cytotoxicity activity of Euphorbia hirta, Euphorbia tirucalli and Euphorbia neriifolia extract against B16F10 melanoma cell line. Inven Impact Ethnopharmacol. 2012;3(3). Available from: http://inventi.in/journal/article/impact/3/3174/ ethnopharmacology/pi

12. Patil SB, Magdum CS. Determination of LC50 values of extracts ofEuphorbiahirta Linn and Euphorbia neriifolia Linn. Using brine shrimp lethality assay. Asian J Res Pharm Sci. 2011;1(2):42-3.

13. Bigoniya P, Rana AC. Immunomodulatory activity of Euphorbia neriifolia leaf hydro-alcoholic extract in rats. Indian Drugs. 2008;45(2):90-7.

14. Gaur K, Rana AC, Chauhan LS, Sharma CS, Nema RK, Kori ML, et al. Investigation of immunomodulatory potential of Euphorbia neriifolia Linn. against betamethasone induced immunosuppression. Int $\mathrm{J}$ Pharmacog Phytochem Res. 2009;1(1):8-11.

15. Yadav RP, Patel AK, Jagannadham MV. Neriifolin S, a dimeric serine protease from Euphorbia neriifolia Linn.: Purification and biochemical characterization. Food Chemistry. 2012;132(3):1296-304.

16. Yadav RP, Patel AK, Jagannadham MV. Purification and biochemical characterization of a chymotrypsin-like serine protease from Euphorbia neriifolia Linn. Process Chem. 2011;46(8):1654-62.

17. Mallavadhani UV, Satyanarayana KV, Mahapatra A, Sudhakar AV. A new tetracyclic triterpene from the latex of Euphorbia nerifolia. Natural Product Research 2004;18(1):33-7.

18. Mallavadhani UV, Satyanarayana KVS, Mahapatra A, Sudhakar AVS, Narasimhan $\mathrm{K}$, et al. Development of diagnostic microscopic and chemical markers of some Euphorbia Latexes. J Integrative Plant Biology. 2006;48(9):1115-21.

19. Ilyas M, Parveen M, Amin KM. Neriifolione, a triterpene from Euphorbia neriifolia. Phytochemistry. 1998;48(3):561-3.

20. Anjaneyulu V, Row LR. The crystalline principles of Euphorbiaceae. Part IV. Curr Sci. 1965;21:608-9.

21. Sharma $V$, Janmeda $P$. Extraction, isolation and identification offlavonoid from Euphorbia neriifolia leaves. Arab J Chem. 2014. http://dx.doi.org/10.1016/j. arabjc.2014.08.019.

22. Sharma V, Janmeda P. Chromatography fingerprinting profile studies on the flavonoids of Euphorbia neriifolia (Linn.) leaves. Int J Drug Dev Res. 2013;5(1):286-96.

23. Mali PY, et al .Pharmacognostical and physico-chemical standardization of Euphorbia neriifolia Leaves. Pharmacog J. 2017;9(5):696-705.

24. International conference on harmonization. Harmonized tripartite guideline. Validation of analytical procedures: text and methodology, Q2 (R1) Geneva. 2005

25. International conference on harmonization. European medicines agency, ICH Topic Q2(R1) - Validation of analytical procedures: text and methodology (Step 5, June 1995, CPMP/ICH/381/95), UK. 1995. 
PICTORIAL ABSTRACT

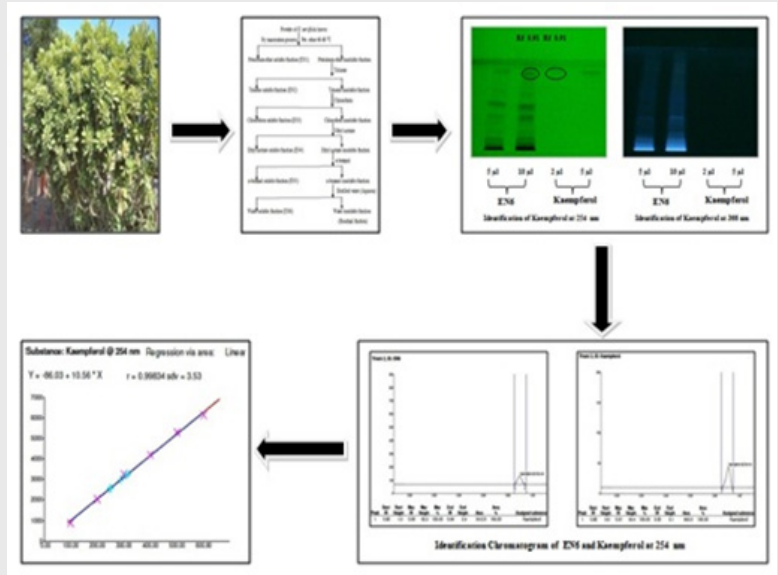

\section{SUMMARY}

The present study was a first report of HPTLC densitometric quantification of kaempferol in aqueous extract fraction (EN6) of leaves of $E$. neriifolia. The method has been validated by $\mathrm{ICH}$ guidelines for its linear range, linearity, LOD and LOQ, specificity, precision, reproducibility and recovery studies. The HPTLC finger printing analysis showed that $R_{f}$ value of peak of kaempferol $\left(R_{f} 0.91\right)$ was closely compacted with aqueous extract fraction (EN6; $R_{f} 0.90$ ) which indicates the identification of kaempferol. The percent content of kaempferol was quantified and found to be $0.024817 \%$ in aqueous extract fraction (EN6) for the $10 \mu$ volume applied. The developed HPTLC method was found to be simple, specific, precise, reproducible and accurate.

\section{About Authors}

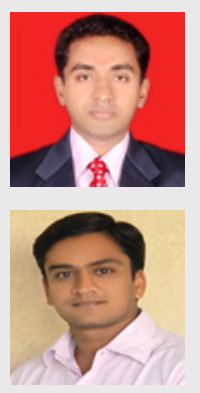

Mr. Prashant Y. Mali is a research scholar at Department of Pharmacology, BR Nahata College of Pharmacy, Mandsaur University, Mandsaur, Madhya Pradesh, INDIA.

Dr. Swapnil Goyal is presently working as Dean Research and Associate Professor in Department of Pharmacy, B. R. Nahata College of Pharmacy, Mandsaur University, Mandsaur. He completed his Ph. D from Uttarakhand Technical University, Dehradun in the field of Pharmaceutical Sciences. He has published several research articles in national and international journals of repute. He has co-authored a book entitled "Drug Discovery and Development in Medicinal Chemistry" by Nirali Prakashan, Pune (Maharashtra). He presented research papers in national and international seminars and conferences like IPSCON, organized by Indian Pharmacological Society. He has handled some sophisticated instruments like HPTLC, UV, HPLC, FT-IR, Autoanalyzer, Non Invasive Blood Pressure (Tail Cuff), Digital Randal-Sellito, Digital Plethysmograph, etc.

Cite this article: Mali PY, Goyal S. HPTLC Densitometric Quantification of Kaempferol from Leaves of Euphorbia neriifolia. Indian J of Pharmaceutical Education and Research. 2020;54(3s):s586-s592. 